\title{
Biotecnologia na nutrição de cães e gatos
}

\section{Maurício Adriano Rocha ${ }^{1}$}

Em primeira estância necessitamos saber o que significa o termo "Biotecnologia", porque este termo está sendo muito utilizado, mas poucas pessoas sabem realmente o que significa.

O termo "Biotecnologia" é a tecnologia baseada na biologia, especialmente quando usada na Agricultura, Ciência dos alimentos e na Medicina. A ciência e tecnologia são duas atividades muito ligadas ao nosso cotidiano. A "Ciência" está associada ao desejo humano de saber, compreendem explicar ou prever fenômenos naturais. A "Tecnologia" decorre de outro desejo: o de encontrar novas e melhores maneiras de satisfazer as necessidades humanas, usando para isso conhecimentos, ferramentas, recursos naturais e energia. As duas atividades, ciência (saber) e tecnologia (fazer) não são totalmente independentes: para poder fazer melhor é necessário sempre saber mais.

A Convenção sobre Diversidade Biológica da ONU possui uma das muitas definições de Biotecnologia:

"Biotecnologia define-se pelo uso de conhecimentos sobre os processos biológicos e sobre as propriedades dos seres vivos, com o fim de resolver problemas e criar produtos de utilidade."

A definição mais ampla da biotecnologia é o uso de organismos vivos ou parte deles, para a produção de bens e serviços. Nesta definição enquadram-se um conjunto de atividades que o homem vem desenvolvendo há milhares de anos, como a produção de alimentos fermentados (pão, vinho, iogurte, cerveja, etc.). Por outro lado a biotecnologia moderna se considera aquela que faz uso da informação genética, a incorporando técnicas de DNA recombinante.

A biotecnologia combina disciplinas, tais como: genética, biologia molecular, embriologia e biologia celular, as quais por sua vez, estão vinculada as disciplinas práticas, tais como: engenharia química, tecnologia da informação e robótica. $\mathrm{O}$ quadro abaixo simplifica muito bem o que é "Biotecnologia":

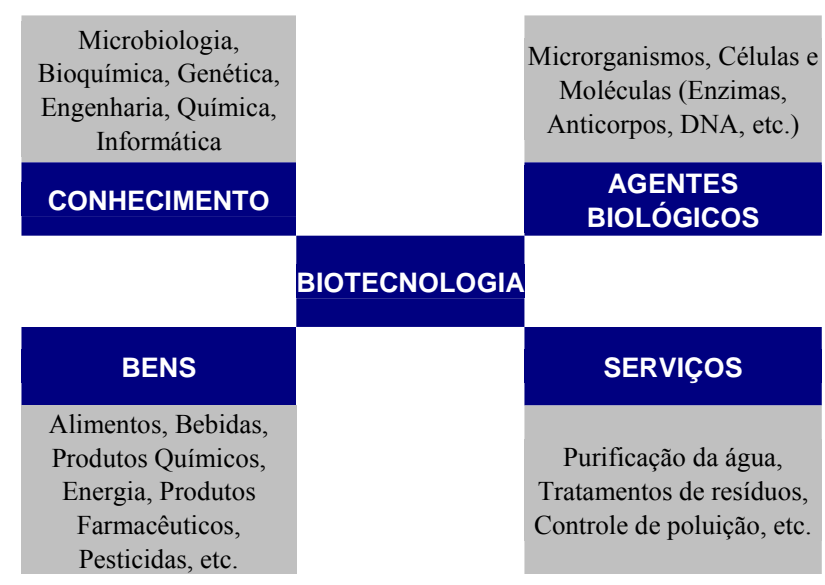

A Biotecnologia já era utilizada na antiguidade, quando o homem fazia pão e bebidas fermentadas; uma das fontes de alimentos dos Astecas eram as algas que eles cultivavam nos lagos. A partir do século XIX, com o progresso da técnica e da ciência, especialmente a Microbiologia, assistimos a grandes avanços na tecnologia das fermentações. No início do século XX desenvolveram-se as técnicas de cultura de tecidos e a partir de meados do século surgem novos horizontes com a Biologia Molecular e com a informática que permite a automatização e o controle das plantas industriais.

No final da década de 70 a Engenharia Genética revoluciona a Biotecnologia "clássica" dando origem ao que denominamos "nova" Biotecnologia. Agora, tornase possível "convencer" uma célula a fazer algo para o qual ela não estava programada. A nova Biotecnologia já tem lançado vários produtos no mercado mundial. Em alguns casos, como os da insulina e do hormônio do 
crescimento, a inovação consiste em substituir os métodos de obtenção tradicionais. Em outros casos, como o dos anticorpos monoclonais, trata-se de produtos inteiramente novos.

A Biotecnologia promove impacto em diversos setores produtivos, seja ela clássica ou moderna, atinge diversos setores, como podemos observar no quadro abaixo:

\begin{tabular}{|c|c|c|}
\hline SETORES & $\begin{array}{c}\text { BENS OU SERVIÇOS OBTIDOS } \\
\text { POR BIOTECNOLOGIA }\end{array}$ \\
\hline AGRICULTURA & $\begin{array}{c}\text { Adubo composto, pesticidas, } \\
\text { silagem, mudas de plantas ou de } \\
\text { árvores, plantas transgênicas, etc. }\end{array}$ \\
\hline ALIMENTAÇÃO & $\begin{array}{c}\text { Pães, queijos, picles, cerveja, vinho, } \\
\text { proteína unicelular, aditivos, etc. }\end{array}$ \\
\hline INDÚSTRIA & QUÍMICA & $\begin{array}{c}\text { Butanol, acetona, glicerol, ácidos, } \\
\text { enzimas, metais, etc. }\end{array}$ \\
\hline \hline ELETRÔNICA & Biossensores, etc. \\
\hline ENERGIA & \begin{tabular}{c} 
Etanol, biogás, etc. \\
\hline MEIO AMBIENTE
\end{tabular} & $\begin{array}{c}\text { Recuperação de petróleo, } \\
\text { tratamento do lixo, purificação da } \\
\text { água, etc. }\end{array}$ \\
\hline PECUÁRIA & \begin{tabular}{c} 
Embriões, animais transgênicos, etc. \\
\hline SAÚDE \\
\hline
\end{tabular} & $\begin{array}{c}\text { Antibióticos, hormônios e outros } \\
\text { produtos farmacêuticos, vacinas, } \\
\text { reagentes e testes para diagnóstico, } \\
\text { células-tronco e novos tratamentos, } \\
\text { etc. }\end{array}$ \\
\hline
\end{tabular}

A Biotecnologia tem provocado inúmeros debates e controvérsias, (biodiversidade, patentes, éticas). Seu futuro dos fatores econômicos e sociais que condicionam o desenvolvimento industrial. Mas, seja como profissionais, seja como cidadãos haveremos de tomar decisões. É neste contexto, ao despontar o século XXI, que mais vez o saber torna-se indispensável.

E através desta busca do saber, a biotecnologia na indústria de alimentação animal, proporcionou recentes avanços na nutrição de cães e gatos através de investigações para melhor entender os detalhes dos requerimentos fisiológicos destes animais.

Como resultado, muitos nutrientes anteriormente não-essenciais agora estão sendo vistos a terem um impacto significativo sobre a saúde e bem-estar destes animais. E este tema a ser abordado neste trabalho discutirá os desenvolvimentos recentes nas áreas de condição de saúde de pele/pêlo, saúde dental, saúde intestinal, envelhecimento, saúde corporal e imunológica.

Quando olhamos para o futuro, o foco esatrá sendo aumentado sobre a influência de nutrientes sobre a área de nutrigênomica. Sobre este desenvolvimento, nós podemos antecipar que nos próximos 5 a 10 anos, permitirá que os produtores de alimentos para animais de companhia providenciaram dietas que otimizem a saúde e bem-estar destes animais através da prevenção de incidências de doenças crônicas e até mesmo modificando genomicamente através da nutrição os possiveis genes dessencadeadores destes problemas. $\mathrm{O}$ desenvolvimento futuro na ciência nutricional para ambos, animais de companhia e seus proprietários, é um caminho promissor, na qual aumentará e prolongará a convivência destes animais com os seus proprietários.

E está sendo muito observado que os propritetários em geral esperam melhorar e prolongar a qualidade de vida de seus animais. Interessantemente, a ligação emotiva demonstratada pelo proprietário para com seu animal, não somente beneficia os animais como os seus proprietários. Pesquisas médicas agora oferecem evidencias conclusivas da ligação positiva anivel psicológico e da influência fisiológica sobre os proprietários (Serpell, 1991; Wilson, 1987; Vormbrock e Grosserg, 1988).

A importância da relação dos proprietários com seus animais para o bem-estar humano tem reforçado, não surpreendentemente, a atenção que tem sido dada sobre estes animais de companhia.

A indústria de alimentos para cães e gatos, em particular, tem respondido aos desejos dos proprietários por oferecerem um amplo grau de produtos que não somente suprem as necessidades nutricionais, mas são designadas para atender um estilo de vida e/ou um estágio da vida do animal, bem como aperfeiçoar as condições associadas com doenças e inabilidade crônica.

Dentro desta busca das indústrias atenderem estes anseios e/ou desejos dos proprietários de cães e gatos, é aonde a biotecnologia entre em uso, para que sejam atendidos com grandes beneficios aos animais e seus proprietários.

Mas quando consideramos estes avanços cientificos na nutrição de cães e gatos, é importante termos em mente que o nosso conhecimento envolvido 
dentro deste desenvolvimento, está interrelacionado em três áreas em especifico :

- Primeiro necessitamos ter um conhecimento do que constitui os requerimentos nutricionais básicos de cães e gatos. A nossa identificação dos fatores que asseguram uma nutrição apropriada continua a expandir uma nutrição ótima;

- Segundo é o nosso conhecimento da fisiologia animal. Como os pesquisadores expandem seus conhecimentos dos links entre a nutrição e sobre tudo do funcionamento do sistema biológico, seus acessos para suprir nutricionalmente tornam-se sempre mais sofisticados e compreensivos.

- Terceiro é o nosso comando de novas tecnologias para a produção de alimentos. $\mathrm{O}$ avanço em equipamentos e metodologias não somente capacitam otimamente a complexidade na variedade e formato do alimento comercial disponível, mas permite o desenvolvimento de novas plataformas para transferência de beneficios nutricionais aos animais.

Temos que entender que o alimento é a parte central de nossoas vidas, por esta razão a produção de certos tipos de alimentos tipificam a nossa idade, nacionalidade e classe social, além de mostrar as condições de nossa saúde no futuro.

Tais atitudes providenciam ainda mais oportunidades para a indústria de alimentos para aplicar desenvolvimentos biotecnológicos e mudanças em niveis de nutrientes para a produção de uma dieta ótima nutricionalmente.

E o uso destes desenvolvimentos biotecnológicos na nutrição animal está se tornando uma ferramenta extremamente importante para indústria, isto porque as pessoas passaram a exigir cada vez mais, alimentos saudáveis - livres de resíduos quimicos e com a capacidade de serem nutraceuticos e o uso destes produtos biotecnológicos vão de encontro com estas necessidades do mercado.

E neste momento nos encontramos em um estágio o qual o uso destes produtos biotecnológicos nos proporcionam uma oportunidade para adicionar estes produtos na nutrição animal, elevando a saúde e bemestar destes animais de companhia para o futuro.

Tais exemplos destes produtos segue abaixo:

- Taurina - De essencial em gatos e benéfico para cães a humanos;
- Vitamina C - De essencial em humanos para condicionalmente essencial em cães e gatos;

- Ácidos graxos polinsaturados de cadeia longa (Omega 3), DHA e EPA (peixe), originalmente na dieta de humanos e cães, perdido durante a evoluação, agora sendo re-introduzido como um nutriente essencial;

- Fitoquimicos - Originalmente com propriedades antioxidantes na dieta de humanos e cães, perdido durante a evolução, agora sendo re-introduzido como nutriente essencial. Aplicação de carotenoides para a saúde ocular em humanos a similar estidos em envelhecimento de cães;

- Metabólitos de Vitamina D - Mostrando ser benéficos em aves para ter um grau de uso em cães e gatos jovens e para aqueles com função hepática dificultada;

- Fito-estrógenos (De linhaça a soja) inapropriado em cães para osteoporose mas possivel para aplicações anticancerígenas;

- Minerais Orgânicos (Quelatos) e Selênio Orgânico - Encontrados como fonte mineral natural e agora sendo substituto de fontes inorgânicas como sendo dados para indicar beneficios sobre e acima dos niveis dos minerais atualmente trabalhados, devido a sua maior absorção pelo organismo;

- Niveis aumentados de vitaminas e carotenóides suplementados da dieta, mostram não apenas suprerar as deficiências clássicas, mas tem um efeito positivo sobre a saúde, expressão genética e células receptoras, por exemplo a facilitação da intensificação imunológica em cães e gatos jovens;

- Extrato de Yucca schidigera - Um agente antiespumante e "Flavor" em bebidas populares de humanos, agora utilizada em alimentos para cães e gatos como "Flavor", redutor de odor fecal e possivel antibacteriano;

Também está sendo adicionados nestas dietas nutrientes especificos e ingredientes alimentares para beneficiar a saúde em longos periodos ou a função bioquimica, que são:

- FOS, MOS, $\beta$-Glucanos - Função imune e saúde intestinal;

- Glucosamina e Condroitina - remodelam a cartilagem e a condição de articulação;

- Nucleotideos - função imune e desenvolvimento da mucosa intestinal;

- Creatinina - Metabolismo muscular; 
- Carnitina - Metabolismo de gorduras;

- Glutamina - imunidade e Status antioxidante;

- Polifenóis de chá - Higiene oral e Status antioxidante;

- Glicomacropeptideos - Higiene oral;

- Poliois - Higiene oral, Função hepática, produção biliar, adoçante, humectante;

- Enzimas - Como auxiliador na produção e como auxiliador na digestão;

- Cromo Orgânico - Anti-diabético;

- Ácido Lipoico - Antioxidante;

- Ervas e Botânicos - várias aplicações;

- Carotenóides (licopeno, Luteína, Zeaxantina) -

- Como antioxidante e facilitador imune;

Atualmente nós estamos começando a identificar evidencias e observações clinicas que sguerem fortemente que os riscos do desenvolvimento de muitas das doenças degenrativas e crônicas são reduzidas pelo consumo de alguns dos previamente chamandos nutrientes dispensaveis e até componentes nãonutrientes (como correntemente defindos) dos alimentos. Adicionalmente, efeitos benéficos sobre a qualidade de vida, nivel de atividade e resistencia a doenças t6em sido observado com a alta ingestão de alguns dos nutrientes essenciais (Harper, 2000). Isto tem levandado questões e encourajado a bioquimica nutricional a re-pensar em ambas as classificações de nutrientes e componentes de alimentos e as quantias que deveriam se ofertados para evitar as deficiências (Lowe, 2002).

Deste modo, antes nós estabelecemos que nível de um nutriente é requerido na dieta para sobrepor a deficiência, então devemos primeiro definir e identificar a condição a qual a deficiência do nutriente estaria associada. Nós agora olhamos para o nivel ótimo aonde a saúde e os marcadores bioquimicos estão otimizados. Neste caminho, os niveis dos nutraceuticos de hoje podem se tornarem o "plus" do amanhã equivalente a nossa redifinição do conceito da deficiência.

O exame de animais geriatricos (Hoskins, 1995) indica que eles raramente sofrem de uma doença singular ou um problema de sistema corporeo, deste modo, o ajustamento para uma combinação de nutrientes para alcançar uma resposta é mais comumente efetiva do que um aumento simples de um único ingrediente.

\section{Como está sendo utilizado esta nova biotecnologia:}

Está nova biotecnologia está sendo utilizada como adicionamento de valor em dietas funcionais, nutraceuticas e também em dietas normais do dia a dia do animal, mas comumente aonde levará um maior ganho para a saúde do animal.

Alguns fabricantes de alimentos para animais de companhia já estão adicionando estes produtos biotecnológicos sem acrecentar em seu rótulo como ingrediente nutraceutico, mas sugerindo que o animal terá os benefícios destes ingredientes.

Embora muitos dos produtos biotecnologicos que nós estamos cientes de sua utilização em dietas para filhotes, simplesmente especificado por beneficios, agora estão se tornando mais e mais aparente como eles se ajustam e estão quase no limite da essencialidade em formulação de dietas para otimizarem a qualidade de vida do animal.

Alguns exemplos da importância destes ingredientes podem ser ilustrados pelo o uso de ANTIOXIDANTES. Muitos acham que o envelhecimento, imunidade, alerta mental e algumas doenças são uma consequência de efeitos acumulativos prejudicias de radicais livres (Baskin e Salem, 1997). A maioria dos radicais livres são produzidos como parte dos processos metabólicos normais do organismo, masem certas condições tanto os radicais livres produzidos pelo organismo animal ou pelos radicais livres que são produzidos por substância ageridas pelo animal aumentam a ocorr6encia destas doenças. O animal possui um sistema elaborado e complexo de defesa antioxidante para tratar de tais ataques violentos destes radicais livres. Entretanto, evidências estão aumentando o indicativo dos beneficios de adicionar antioxidantes em dietas para dar suporte ao sistem de produção própria do organismo, e sabemos que o adicionamento de mais de um antioxidante teremos um efeito sinérgico no combate aos radicais livres produzidos no organismo.

A inclusão de vitaminas como fator antioxidante, tais como a Vitamina $\mathrm{E}$ e $\mathrm{C}$ têm modificado dramaticamente nos últimos anos. Há evidências que 
cães em período de reprodução e lactação necessitam de alta quantia de Vitamina $\mathrm{E}$, mas as quantia utilizadas para que venham proporcionar beneficios aos animais, é necessário levar em conta, as possiveis perdas pelo processo de oxidação de óleos e gorduras nas dietas como também as necessidades em cada estágio de vida do animal.

Os requerimentos da Vitamina $\mathrm{E}$ em dietas para animais de companhia agora também está levando-se em conta a utilizaçào de um novo ingrediente esquecido pela nutrição animal como um fator dantioxidante, que é o selênio (Se), devido a sua importância na conjunção com a Glutationa Peroxidase (GSHPx). Pesquisas demonstram que a Vitamina E e conjunção ao Selênio, possuem um efeito sinérgico no combate aos processo de oxidação celular, permitindo uma maior preservaçào do pâncreas, que eleva a uma maior digestão da gordura e aumentando a absorção da vitamina E pelo organismo. Isto porque o Selênio Orgânico reduz a quantidade de Vitamina E necessária para manter a integridade dos lipideos da membrana, mediante a uma maior atuaçào da Glutationa Peroxidase (GSHPx) e leva a uma maior retenção da Vitamina $\mathrm{E}$ integra no plasma sangüíneo.

Em estudos recentes, indicam que $\mathrm{o}$ melhoramento na capacidade de antioxidante total dos cães pode ser alcançada com altos niveis de inclusão de Vitamina E e com inclusões em excesso de $500 \mathrm{mg} \cdot \mathrm{kg}^{-1}$ para reduzir os alcalóides circulantes no soro sanguineo (Jewel et al 2000) e como parte de uma mistura de outros antioxidantes, estatus imune (Harper, 2001).

Os antioxidantes possuem uma variedade de funções com o organismo, todos os quais estão envolvidos com a redução nos danos oxidativos. Os muitos antioxidantes do animal, desde de as vitaminas até as enzimas endógenas podem ser agrupadas de acordo com o seu grau na prevenção e redução das reações oxidativas, potencial REDOX e relativas concentrações das moléculas circundante, com as vitaminas primárias atuantes como sequestradores de radicais livres.

Por exemplo baseado em suas relativas atividades sequestrantes de radicais livres, o Licopeno, $\beta$-caroteno, Luteína=zeaxantina (ambos possuem similares estruturas), $\quad \alpha$-caroteno, $\quad$ cantaxantina $=$ astaxantina (Milleret al 1996). A eficiência por de trás dos carotenóides não é somente em suas abilidades em sequestrar radicais livres e atuar como antioxidantes de quebra de cadeia de radicais livres, mas também atuar através da formação de adução de radicais em que eles próprios são altamentes estáveis e atuam para finalizar as reações de radicais livres.

A ação dos carotenóides em termos de realçadores da função imunológica aparece ser através de muitos modos de ação; proliferação de limfócitos aumentada, células T-auxiliadoras e a regulação elevada da interleucina-2 enquanto deprime a prostaglandina E2 resultando em um todo a elevação da resposta humoral. É também considerado que a integridade das membranas das células imune são realçadas pelo sistema antioxidante.

Em grau de similaridade há para os extratos de plantas da Yucca schidigera, em que suas inclusões em dietas de cães e gatos têm sido demonstrato a melhora na intensidade de aroma fecal e altera os gases volateis das fezes (Lowe e Kershaw 1997, Lowe et al 19971). Entretanto, há também informações sobre a sua eficiência na redução de processos inflamatórios e artrites em humanos (bingham 1975). Ademais, as saponinas esteróides são relatadas em reduzir os niveis de colesterol (Bingham et al 1978) e influencia na apoptose celular cancerigena (Sakagami et al 2001) sua presença na Yucca schidigera pode então ser de beneficio adicional para os cães.

Da mesma maneira a utilização de oligossacarídeos como fator prebiótico em dietas de cães e gatos demonstram uma efetividade na seleção do crescimento e atividade de bactérias benéficas a nivel intestinal, melhorando a saúde do animal (Gibson e Roberfroid 1995). Os Mananoligossacarideos são adquiridos da parte externa da parede celular da levedura $\mathrm{e}$ os Fructoligossacarideos ocorrem naturalmente de alimentos tais como: trigo, cebola, bananas e alho.

Pesquisas cientificas têm demonstrado que estes oligossacarideos promovem uma melhora substâncial na concentração de bactérias benéficas (Bifidobacterium e lactobacillus) e da mesma maneira reduzem a concentração de bactérias prejudicias à membrana intestinal, tais como C. perfringens e E. Coli (swanson, 2001), melhorando a saúde intestinal do animal, diminuindo as condições favoraveis ao aparecimento de problemas entéricos. 
Da mesma maneira, pesquisas demonstraram que o uso de Bio-Mos em tratamento de doenças entéricas em dose terapeuticas auxiliam em um recuperação mais rapida dos animais enfermos, melhorando a saúde imunológica e intestinal do animal, através da aglutinaçào de bactérias patogênicas (Gouveia 2004).

Swanson 2001, demonstrou que a utilizaçào de FOS e MOS conjuntamente elevou a concentração de IgA, melhorando a resposta imunitária dos animais. Da mesma maneira, O'Carra, 1996, demonstrou que a utilização de 2 grs de Bio-MOS / $\mathrm{kg}$ de dieta melhorou a resposta imunitária dos animais durante o processo de vacinação, aumentando a imunização destes animais.

Ultimamente estão sendo utilizados novos produtos biotecnológicos na busca de uma maior eficiência na saúde intestinal, imunologica, hepatico e nervoso. Recentes estudos com o uso de nucleotídeos têm demonstrado que este ingrediente favorece um menor gasto energético na metabolização hepatica preservando todo sistema digestivo e melhorando a digestão dos alimentos, como também está envolvido em reações essenciais para a manutenção e propagação da vida.

Está constato que a utilização de nucleotídeos, que ocorrem naturalmente no leite materno, é essencial para promover um melhor desenvolviemnto da mucosa intestinal, diminuindo as possibilidades de ocorrerem problemas entéricos nos primeiros dias de vida.

Estudos recentes demonstraram que a utilização de um composto à base de nucleotídeos, inositol, ácido glutâmico e peptídeos (NUPRO)- melhoram a palatabilidade das dietas caninas (Aulus 2006). Rutherford-Marwick 2005, demonstraram que gatos alimentados com uma dieta com Nupro tiveram um aumento significativo na proliferação de linfócitos e da atividade fagocitáriados leucócitos, além de melhorar significativamente a resistência e a capacidade de combater doenças e infecções felinas.

Além destes novos produtos biotecnológicos, o uso ideal de minerais de traço é essencial na prevenção de doenças e na mantença de um organismo saudavel. A absorção destes minerais sofrem interferências diretas de dietas de baixa digestibilidade, alta viscosidade intestinal, interação entre os próprios minerais, baixa biodisponibilidade e retenção dos mineirais inorgânicos como também da interferência da alta concentraçào de fitado na dieta. Desta maneira, o organismo animal não terá uma concentração ótima dos minerais essenciais para a mantença de sua saúde, reduzindo a imunidade, baixa saúde do sistema dermatológico, baixo desenvolvimento animal e reduzida sintese de colágeno.

Lowe et al 1996, demonstrou que a utilização de novas biotecnologias na produçào de minerais de traço na forma de quelatos, se faz necessário para se obter uma melhor saúde do animal. Através de um trabalho com a utilizaçào de Zinco Orgânico, ele demonstrou que o calcio não interfere na biodisponibilidade do zinco orgânico, melhorando a sua deposição a nivel de pêlo. Em outra pesquisa cientifica, foi demonstrado que os minerais orgânicos são mais biodisponiveis, sendo absorvidos e retidos no organismo em uma maior procentagem quando comparado com os minerais inorg6anciso, isto devido a uma menor interação entre os próprios minerais (Lowe e Wiseman 1997).

Em uma recente pesquisa cientifica, Borges et al 2004 demonstrou que a utilização de Zinco na forma Orgância em dietas de gatos, aumentou a sua biodisponibilidade e retenção no organismo, comprovando a eficiência da utilização destes minerais na forma orgânica na prevenção de doenças por baixa concentração destes minerais.

Além dos avanços biotecnológicos da produção de alimentos funcionais e terapeuticos na busca intensiva de levar aos animais uma melhor saúde e bemestar, as empresas agora estão tendo altas preocupações com as últimas ocorrências na contaminação dos alimentos por materias-primas contaminadas. Estes contaminantes estão fazendo com que as empresas venham utilizar de novas tecnologias no controle de entrada de matérias-primas e aumentando o controle de qualidade para que os alimentos não venham levar aos animais danos a sua saúde. Mas um dos contaminantes que está elevando a preocupaçào dos fabricantes é a presença de micotoxinas. As micotoxinas são metabólitos produzidos por fungos que estão presentes em mais de $25 \%$ de todo os grãos produzidos mundialmente. Desta maneira as empresas produtoras de alimentos de animais de companhia estão fazendo uso de novas biotecnologias para eliminar este contaminante de alta agressividade à saúde animal.

Esta nova biotecnologia que está sendo utilizada a nivel mundial são os adsorventes orgânicos. Estes adsorventes orgânicos que são glucomananos são 
produzidos através da hidrolise enzimatica da parede celular da levedura. Este novo produto biotecnológico está sendo comprovado como uns dos melhores adsorventes de micotoxinas utilizados na industria de alimentaçào animal.

Em estudos recentes, Sala et al 1997, demonstrou que o adsorvente a base de glucomananos adsorvem micotoxinas em diferente concentrações de adsorção apra cada micotoxina, sendo extremamente eficaz na adsorção de aflatoxinas, Zearalenona, fumonisina e T2. Evans 2000, demonstrou que os glucomananos adsorvem as micotoxinas mesmo em baixas concentrações de uso como também adsorvem as micotoxinas mesmo em diferentes $\mathrm{pH}$ e concentrações de micotoxinas. Entretanto, o uso destes adsorventes orgânicos não corrigem erros de controle de qualidade da empresa, sendo assim necessário a utilização de nova tecnologias de controle de qualidade para se elevar a preservação da saude e bem-estar do animal.

\section{Conclusão}

A inclusão destas novas biotecnologias nos alimentos para cães e gatos têm sido visto por todos o lados como um fator necessário para melhorar as margens dos fabricantes, melhorar o valor de percepção pelo proprietário e também melhorar a perspectiva de qualidade de vida do animal.
A utilização destas novas tecnologias abriu novas formas de se buscar a prevenção e o tratamento de doenças através do alimento ofertado no mercado, elevando assim, a amrgem e a percepção de valor pelo cliente.

Muito da disponibilidade dos produtos biotecnológicos agora ofertados, pelo menos um se encontra nas dietas e em muitos casos todos estes requerimentos para serem cumpridos devem ser através de benefícios individuais identificaveis em vendas e através de seu envolvimento na imagem da completa nutrição animal.

\section{Referências}

$\uparrow$ "Convenção sobre Diversidade Biológica (Artigo 2. Utilização de Termos)." Nações Unidas. 1992. Recuperado em 27 de março de 2008.

$\uparrow$ Bunders, J.; Haverkort, W.; Hiemstra, W. "Biotechnology: Building on Farmer's Knowledge". Macmillan Education, Ltd, 1996. ISBN 0333670825

$\uparrow$ Henco, A. International Biotechnology Economics and Policy: Science, Business Planning and Entrepreneurship; Impact on Agricultural Markets and Industry; Opportunities.

K. E. Earle BSc, PhD, Director of Nutritional Products, Friskies Product Technology Center, U.S.A. - Recent advances in pet nutrition 